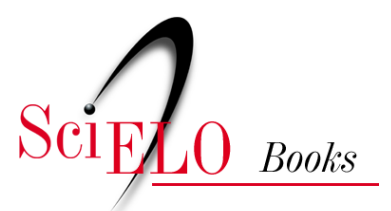

\title{
3. Formulação e implementação de Políticas de Saúde no Estado do Rio de Janeiro
}

\author{
Silvia Gerschman
}

\section{SciELO Books / SciELO Livros / SciELO Libros}

GERSCHMAN, S. Formulação e implementação de Políticas de Saúde no Estado do Rio de Janeiro. In: UGÁ, M.A.D., et al., (orgs.). A gestão do SUS no âmbito estadual: o caso do Rio de Janeiro [online]. Rio de Janeiro: Editora FIOCRUZ, 2010, pp. 69-88. ISBN: 978-85-7541-592-4. Available from: doi: $10.7476 / 9788575415924.0005$. Also available in ePUB from: http://books.scielo.org/id/c2hxb/epub/uga-9788575415924.epub.

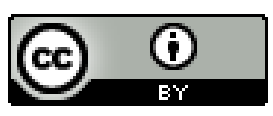

All the contents of this work, except where otherwise noted, is licensed under a Creative Commons Attribution 4.0 International license.

Todo o conteúdo deste trabalho, exceto quando houver ressalva, é publicado sob a licença $\underline{\text { Creative Commons }}$ Atribição 4.0. 


\section{Formulação e Implementação de Políticas de Saúde no Estado do Rio de Janeiro}

\section{Silvia Gerschman}

Este capítulo é resultado de um estudo preliminar sobre as políticas de saúde no estado do Rio de Janeiro, sendo o Sistema Único de Saúde (SUS) o foco principal. Analisar a formulação e implementação da política de saúde nos anos recentes e na gestão atual requer compreender como o SUS foi incorporado à política e à gestão da saúde estadual.

Desde a Constituição de 88 (CF88), que define o SUS como um sistema único de saúde, integrado e descentralizado em estados e municípios, a ser implementado com direção única em todo o país, ambos - estados e municípios - foram convocados a desenvolver e formular políticas locais capazes de instituir a ideia plasmada no processo constituinte e consagrada na Constituição do país.

Para o desenvolvimento do SUS, criaram-se mecanismos de mediação entre as três esferas de governo. Estes foram de distinta ordem: de uma parte, leis complementares, resoluções, portarias e normas operacionais que tiveram o papel de definir de maneira detalhada os princípios constitucionais e procedimentos a serem seguidos, seja no que se refere ao sistema e financiamento como um todo, seja quanto a suas partes - prevenção, atenção, programas e serviços. De outra parte, o SUS gera um processo formal de institucionalização nas esferas de governo que dele participam, através da formação de instâncias que vão estabelecer as mediações entre e dentro da federação, estados e municípios. Refiro-me à Comissão Intergestora Tripartite (CIT) - com participação de representantes do Ministério da Saúde, da Comissão de Secretários Estaduais (Conass), da Comissão de Secretários Municipais (Conasems) - e à Comissão Intergestora Bipartite (CIB) no âmbito de cada estado com representação do governo estadual e dos governos municipais. Elas desempenham a função de pactuação das políticas entre esferas de governo na saúde.

Além disso, foram formuladas instâncias institucionais de participação da sociedade na deliberação da política de saúde nas três esferas de governo, os denominados Conselhos de Saúde. A saber: o Conselho Nacional de Saúde (CNS), os Conselhos Estaduais de Saúde (CES) e os Conselhos Municipais de Saúde (CMS). 
Não obstante a política estar consideravelmente definida no que se refere ao processo de institucionalização, aos procedimentos de gestão e financiamento e à incorporação de mecanismos legais de indução para a operacionalização, repasse e alocação de recursos financeiros, o processo de interiorização do SUS no estado vem atravessando sérios problemas no período pós-constitucional.

Na primeira parte do capítulo, apresentaremos um perfil populacional, de serviços e do desenvolvimento do setor assistencial público e privado no estado como subsídio para discutirmos a 'crise' que atravessa a implementação da política estadual de saúde desde o final dos anos 80, após a aprovação da CF88 e da subsequente Constituição Estadual de 1989.

Na segunda parte, consideraremos a descentralização das políticas de saúde e as dificuldades que se apresentam à inclusão do estado no processo de integração e pactuação federativa, tal como idealizado constitucionalmente.

$\mathrm{Na}$ terceira parte, consideraremos, como chave explicativa para a compreensão do incipiente desenvolvimento do SUS no estado, a especial configuração política gerada pelo processo da fusão entre o estado de Guanabara, criado pela transferência da capital do país para Brasília, com o antigo estado do Rio de Janeiro.

Na quarta parte, discutiremos o surgimento, o papel e a interferência da máquina política estadual para o estabelecimento de um pacto federativo necessário para a descentralização do sistema de saúde estadual.

As considerações finais retomam as dificuldades de interiorização do SUS por conta das políticas partidárias que, historicamente, marcaram a existência do estado do Rio de Janeiro.

\section{Alguns Indicadores Relevantes para a Compreensão da Política Estadual}

Os dados a seguir relativos à população e à evolução do número de estabelecimentos iniciam em 1980, após a fusão do estado de Guanabara com o estado do Rio de Janeiro, por considerar que este foi um marco político extremamente significativo na história das políticas estaduais. Os anos-base de comparação são 1990 e 2005, porque para estes anos existem informações sobre população e estabelecimentos. No que se refere aos dados relativos ao papel da esfera pública e privada no SUS, utilizamos as estatísticas mais recentes publicadas pelo IBGE/MAS (Brasil/IBGE, 2005) e DataSus (Brasil, 2007).

Os dados demográficos da região Sudeste mostram que, em 1980, a população de São Paulo representava quase a metade da população da região e, em 2005, esse número aumenta em três pontos percentuais. Diferentemente, no Rio de Janeiro, a população que, em 1980, correspondia a 20,5\% da região Sudeste diminui, no período, dois pontos percentuais. Já em Minas Gerais, houve uma redução de um ponto percentual, ao passo que no Espírito Santo se mantém sem mudanças significativas. 
Em relação à evolução dos estabelecimentos de saúde, em 1980, a região Sudeste $(43,1 \%)$ concentrava pouco menos que a metade dos estabelecimentos existentes no Brasil. O número de estabelecimentos diminui para 36,7\% em 2005. Ainda que nos quatro estados da região tenha crescido o número de estabelecimentos, entre 1980 e 2005 diminuiu a participação percentual do Rio de Janeiro na região Sudeste (de 20,6\% para 18,0\%) assim como também de São Paulo (de 41,7\% para 38,3\%), ao passo que aumentou a participação de Minas Gerais (de 32,2\% para 37,3\%) e do Espírito Santo (de 5,5\% para 6,2\%). Cabe acrescentar que, ao comparar apenas o número de estabelecimentos de saúde entre os estados, observa-se que o Rio de Janeiro possui quase a metade dos estabelecimentos existentes em Minas Gerais e em São Paulo para o ano de 2005.

A despeito de existir uma diferença populacional entre Rio de Janeiro (de 11.291.631 em 1980 para 13.807.368 em 2005) e Minas Gerais (de 13.380.105 em 1980 para 19.237.434 em 2005), ela não explica o crescimento tão significativo de estabelecimentos em São Paulo (de 3.139 para 10.839) e Minas Gerais (de 2.427 para 10.592) do que no Rio (de 1.554 para 5.085). Ou seja, a diferença do crescimento dos estabelecimentos de saúde é muito maior entre esses estados do que a variação de população poderia explicar.

Aos dados demográficos e ao número de estabelecimentos, serão acrescentados alguns indicadores para o ano de 2008 de modo a comparar o Rio de Janeiro com os outros estados da região no que se refere ao tipo de estabelecimentos, à capacidade instalada e à sua utilização.

O tipo de estabelecimentos foi analisado levando em consideração a disponibilidade de dados existentes nas diversas fontes consultadas. Os dados mais recentes correspondem a dezembro de 2008 e são estes os considerados aqui.

O maior número de estabelecimentos na região Sudeste corresponde a centros de saúde/unidades básicas de saúde (10.361) e clínicas/ambulatórios especializados (11.621). O número de postos de saúde (2.497), policlínicas (1.936) e hospital geral (1.760) é bem menor.

O Rio de Janeiro tem uma participação bem menor de centros de saúde/UBS (14,5\%) e clínicas/ambulatórios (17,9\%) que Minas Gerais, cuja participação percentual desse tipo de serviços na região Sudeste é bem maior (39,2\% e 24,5\%, respectivamente). Nas restantes categorias - hospital geral, policlínicas e pronto-socorro -, a participação dos estabelecimentos do Rio de Janeiro na região é de aproximadamente 20\%. Em Minas Gerais, o número de postos de saúde e hospital geral é elevado, enquanto em São Paulo o número é elevado em todos os tipos de estabelecimentos, a exceção de postos de saúde. A menor participação é do Espírito Santo. Apenas o número e a participação do Rio de Janeiro é maior que a dos outros estados, no que se refere a hospitais especializados (238) e postos de saúde (648).

No que se refere à capacidade instalada e à utilização dos estabelecimentos de saúde, medidos pelo indicador leitos por 1.000 habitantes, observou-se uma variação percentual negativa entre 1990 e 2005 bastante significativa. No Rio de Janeiro, a variação percentual dos leitos foi de $-77,1 \%$ no espaço de 15 anos. Em São Paulo, a diminuição foi a mais 
elevada de toda a região Sudeste (-164,6). Em Minas Gerais, foi bastante menos pronunciada e no Espírito Santo foi a menor da região Sudeste.

Tabela 1 - Leitos por 1.000 habitantes e variação percentual nos estados da região Sudeste - 1990-2005

\begin{tabular}{l|c|c|c|c}
\hline L/1.000H ANO & MG & ES & RJ & SP \\
\hline Ano 1990 & 3,83 & 3,22 & 5,19 & 6,06 \\
\hline Ano 2005 & 2,41 & 2,24 & 2,93 & 2,29 \\
\hline Variação percentual & $-58,9$ & $-43,7$ & $-77,1$ & $-164,6$ \\
\hline
\end{tabular}

Fonte:< tabnet.datasus.gov.br/tabcgi.exe2idb2007>

As internações por 100 habitantes para o ano de 2006 - último ano consignado pelas fontes - no Rio de Janeiro $(4,49)$ são menores do que em Minas Gerais $(6,10)$, Espírito Santo $(5,43)$ e São Paulo $(5,50) .{ }^{1}$ Como não há por que supor que as necessidades na utilização de internação sejam menores no Rio de Janeiro do que nos outros estados, cabe apenas apontar para a possibilidade de que a diferença na utilização desse serviço obedeça a dificuldades com esse tipo de atendimento. Essa questão voltará a ser considerada no ponto relativo à esfera público/privado no estado.

O número de consultas médicas por habitante/ano em 2006 foi de 2,77 no Rio de Janeiro; 2,40 em Minas Gerais; 2,82 no Espírito Santo; e 3,15 em São Paulo. ${ }^{2}$ Ou seja, o número de consultas pode ter sido influenciado pela dificuldade de acessar o serviço ou devido a menor procura da população por consultas médicas.

As dificuldades do sistema estadual revelam-se na análise dos dados apresentados e poderiam ser sintetizadas na diminuição dos estabelecimentos de saúde, no número bastante menor de vários tipos de estabelecimentos, tais como centros de saúde, clínicas, hospital geral, policlínicas, comparado com Minas Gerais e São Paulo; assim como a diminuição da capacidade instalada e taxas de internação mais baixas que as dos outros estados.

Ainda que a notória ênfase que a política nacional vem dando às políticas de atenção primária possa incidir na diminuição de estabelecimentos, taxas de internação e outros indicadores, enquanto as mudanças das práticas terapêuticas no que se refere à diminuição do tempo de internação e do número de leitos incidam sobre o número de estabelecimentos que requerem internação, todas essas transformações têm a mesma intensidade para todos os sistemas de saúde estaduais. Vale dizer que todos esses aspectos não são suficientes para compreender as dificuldades mais amplas observadas no Rio de Janeiro.

Justificar a ingovernabilidade do sistema de saúde pelo tamanho da rede também não parece argumento adequado. Contudo, em declaração recente, o secretário de Saúde Municipal do Rio de Janeiro manifestou que "a rede do município do Rio de Janeiro tem

\footnotetext{
1 Ver Brasil/MS (2007).

2 Ver Brasil/MS (2007).
} 
o maior número de instituições públicas de saúde do país sob a gestão de diferentes esferas de governo" (Conasems, 2007).

Essa afirmação, tão reiterada ao longo do tempo, é tomada por verdadeira e, como toda verdade, inquestionável. Desde a época da fusão do estado de Guanabara com o do Rio de Janeiro, os políticos atribuem os problemas dos serviços públicos hospitalares no Rio à dificuldade de gerir um número demasiado grande de estabelecimentos de saúde.

\section{Desenvolvimento do Setor Público e Privado}

Além dos dados populacionais, da capacidade instalada e da utilização dos serviços, incorporamos alguns indicadores que nos possibilitam fazer inferências sobre o desenvolvimento do padrão específico público/privado predominante no Rio de Janeiro assim como do padrão regional. Considerando que a CF88 estabelece que o sistema de saúde seja de caráter universal e público passamos a levantar os dados/indicadores do padrão público e privado prevalecente no estado do Rio de Janeiro.

Observamos inicialmente que na região Sudeste a proporção de estabelecimentos públicos e privados é muito semelhante, praticamente existem o mesmo número de uns e outros. No Rio de Janeiro, há uma diferença bastante significativa de 22 pontos percentuais a mais de estabelecimentos privados. Em São Paulo, a diferença é menos significativa e corresponde a 7 pontos percentuais a mais de estabelecimentos privados enquanto em Minas Gerais a diferença se inverte, acusando 19 pontos percentuais a mais de estabelecimentos públicos do que privados. Por último, no Espírito Santo também prevalecem os públicos com uma diferença de 10 pontos percentuais a mais (Tabela 2).

Tabela 2 - Estabelecimentos por esfera administrativa nos estados da região Sudeste - 2005

\begin{tabular}{l|c|c|c}
\hline \multicolumn{1}{c|}{ Regiões } & TOtAL & Público & PRIVAdO \\
\hline Região Sudeste & 28.371 & 14.337 & 14.034 \\
& $(100 \%)$ & $(50,5)$ & $(49,5 \%)$ \\
\hline \multirow{2}{*}{ MG } & 19.592 & 6.343 & 4.249 \\
& $(100 \%)$ & $(59,8)$ & $(40,2)$ \\
\hline ES & 1.755 & 958 & 797 \\
& $(100 \%)$ & $(54,5)$ & $(45,4)$ \\
\hline \multirow{2}{*}{ RJ } & 5.085 & 1.982 & 3.103 \\
& $(100 \%)$ & $(39,0)$ & $(61,0)$ \\
\hline SP & 10.939 & 5.054 & 5.885 \\
& $(100 \%)$ & $(46,2)$ & $(53,8)$ \\
\hline
\end{tabular}

Fonte: Brasil/IBGE (2005).

No que se refere ao tipo de atendimento, a maioria dos estabelecimentos públicos da região Sudeste é sem internação $(92,8 \%)$ e muito poucos contam com internação. Nos estados observa-se tendência similar, e o Rio de Janeiro acusa 3 pontos percentuais a mais de estabelecimentos públicos com internação do que Minas Gerais e São Paulo. 
Nesses estabelecimentos públicos, um número muito pequeno dos mesmos oferece Apoio Diagnóstico e Terapia. Chama a atenção o fato de que nos estabelecimentos privados se revele a mesma tendência encontrada nos públicos, a maioria destes não possui internação; mas, diferentemente, um alto número dos estabelecimentos privados operam com Apoio Diagnóstico e Terapia.

Os leitos por mil habitantes no setor privado que acompanham as tendências encontradas na análise do tipo de atendimentos público/privado são maiores que em todos os estados. Rio de Janeiro, Minas e São Paulo possuem os indicadores mais altos de leitos privados por mil habitantes.

Como observado, os estabelecimentos privados são predominantes no estado, e em ambos, privados e públicos, o número de estabelecimentos com internação é muito baixo em relação aos que não possuem internação. Também os atendimentos de apoio a diagnose e terapias, ou seja, complementares a todo tipo de atendimento, são predominantemente privados: apenas 75 estabelecimentos com apoio a diagnose são públicos ao passo que 1.167 são privados.

Naturalmente a relação entre os setores público e privado é marcada pelas desigualdades existentes entre ambos os sistemas. As situações de crise no atendimento à população do município e estado apenas atualizam os problemas histórico-estruturais do sistema de saúde municipal e estadual; os dados observados ilustram os empecilhos da gestão e da implementação do SUS no estado do Rio.

A própria denominação 'Sistema Único de Saúde' envolve significado explícito, relacionado ao caráter universal e único do sistema de saúde. Mas isso não condiz com o significado real do que seja o sistema de saúde no Brasil, ao fato empírico de este ser composto por diferentes sistemas. Existem pelo menos três sistemas: o público propriamente dito, o privado e o filantrópico. Este último com suas variantes com e sem fins de lucro. Essa aproximação ao efetivo caráter do sistema de saúde no país exige que as políticas sejam diferenciadas e adequadas a cada uma dessas esferas - público, privado e filantrópico. Mas a respeito dessa condição de não ser de fato um único sistema, a Constituição faz uma referência ambígua que facilita leituras diversas. ${ }^{3}$

\section{A Crise da Política ou a Política da Crise na Saúde Estadual}

As dramáticas situações de adoecimento que vêm sendo enfrentadas pela sociedade carioca se tornaram habituais e, ainda que reiteradas e permanentes, são correntemente denominadas na imprensa, por políticos e na própria literatura acadêmica da área, de 'crises'.

Essas 'crises' comportam a conjunção de um amplo leque de problemas e se caracterizam pela ausência de políticas de prevenção - tais como a luta contra a dengue -, pela falência continuada de serviços de atenção à saúde, pelas dificuldades em oferecer atendimento satisfatório à população e pelas permanentes filas de espera.

Acreditamos que os problemas no setor da saúde se manifestem de maneira mais severa na capital e na região metropolitana do Rio de Janeiro, por ser neste espaço regional que

\footnotetext{
3 Ver Gerschman (2008).
} 
se concentra a maior parte da população do estado e dos serviços de assistência e atenção à saúde, e também pela própria história política: o fato de ter sido capital da República e estado antes da fusão. Neste capítulo, não foram tratados os dados do município de Rio de Janeiro, da região metropolitana e do interior do estado de maneira separada.

Em 2005, o governo federal, pelo decreto n. 5.392, interveio nos seis hospitais mais importantes da cidade. Quatro deles haviam sido municipalizados quando o município se habilitou à Norma Operacional Básica de 1996 (NOB 96)4 do Ministério da Saúde (Lagoa, Ipanema, Andaraí e Cardoso Fontes). Os outros dois (Miguel Couto e Souza Aguiar) já estavam sob a jurisdição municipal antes da NOB 96. É nessa oportunidade que a prefeitura do Rio de Janeiro perde, por decisão do Conselho Municipal de Saúde, a condição de 'Gestão Plena Municipal' do SUS.

No Rio de Janeiro, a epidemia de dengue continua a ser uma ameaça permanente para a saúde dos cariocas. Em abril de 2008, ela ressurgiu de maneira bastante virulenta quando a expectativa da população, que se frustrava reiteradamente, era debelar epidemia após epidemia - em 2002, 2003, 2006, 2007. Em 2007, 57.599 pessoas foram contaminadas pelo mosquito e, em 2008, estimava-se que houvesse mais de 52.000 casos. ${ }^{5}$ Segundo dados da SES, o maior número de pacientes com a doença tem se concentrado no município do Rio de Janeiro e na região metropolitana.

Como explicar que a dengue apareça novamente sobre forma mais virulenta que nas epidemias passadas? Diversos fatores influem para que isso aconteça. Dentre os problemas cabe destacar: a precariedade no abastecimento de água, a estocagem desta em grandes reservatórios permanentes, a existência de terrenos baldios e a heterogeneidade socioespacial da cidade (Siqueira, 2008).

Ainda deve-se notar que, nos últimos anos, as secretarias de saúde do governo do estado e do município do Rio não tiveram uma política de contratação regular de agentes de saúde para distribuir nos domicílios e à população o produto para combater as larvas do mosquito.

Uma maior contratação de equipes do Programa de Saúde da Família poderia ter contribuído para minimizar a crise e para a melhoria da saúde da população mais carente. Aliás, segundo declarações recentes do ministro da Saúde, José Gomes Temporão, existe uma baixíssima cobertura do Programa de Saúde da Família no estado e no município do Rio.

As políticas de saúde deixaram de ser políticas sociais e universais para se tornarem políticas balizadas pelo mercado. Esse é o aspecto central e não mencionado nos discursos dos sucessivos governos do município e do estado: a obrigatoriedade constitucional que o estado tem de investir em políticas de bem-estar da sociedade. Curiosamente, as manifestações públicas dos governos, tal como noticiado pela imprensa nos últimos anos, têm

\footnotetext{
${ }^{4}$ Tardiamente, em 1999, o município conseguiu reunir os requisitos exigidos pela Norma Operacional Básica de 1996, conhecida como NOB 96, para se habilitar à condição de Atenção Plena da Gestão Municipal.

${ }^{5}$ Ver Dengue $(2007,2008)$.
} 
sido a escassez de recursos financeiros para a implementação do sistema e dos serviços de saúde no município e no estado do Rio de Janeiro.

Considerando que a implementação de um sistema de saúde público e universal está na pauta das políticas de saúde desde a aprovação do SUS na Constituição Estadual, cabe se perguntar: por que as políticas de saúde carecem dos recursos necessários para sua efetivação? Trata-se de insuficiência de recursos ou trata-se de uma política de desinvestimento dos sucessivos governos do estado do Rio de Janeiro?

\section{A Descentralização da Política de Saúde Estadual}

A descentralização a partir dos anos 90, quando se consolida o projeto constitucional em sua feição atual, é compreendida na instância federal como um processo gradual que parte da atenção à saúde e aos seus serviços até conquistar a prevenção e promoção da saúde, alcançando-se a implantação completa do SUS. Assim se implantariam as bases para uma saúde pública universal capaz de incorporar ao sistema todas as regiões com suas disparidades e todos os grupos populacionais. Para sua efetivação, constituíram-se instrumentos de gestão que se mostram extremamente sensíveis aos processos políticos e grupos de interesse da área da saúde, às políticas preexistentes entre instâncias federadas União, estados e municípios - e aos processos políticos próprios de estados e municípios.

Diferentemente do que seria desejável e previsível, existem poucos trabalhos que discutem o processo de descentralização da política de saúde no estado do Rio. Ao nos debruçar sobre a bibliografia, nos deparamos com a dificuldade de não haver importante produção de pesquisa e bibliografia de políticas de saúde no estado. Estranhamente, também não se registra produção abundante no campo da ciência política sobre a problemática bastante idiossincrática das políticas públicas no estado após a fusão.

A descentralização da política de saúde é um dos pontos neurálgicos do SUS no estado. Para analisá-la devemos considerar que a referência ao SUS sempre é imprecisa, dado que a descentralização se refere apenas às políticas desenhadas para o desenvolvimento do sistema público de saúde. Neste sentido, o SUS traz embutida uma contradição de difícil resolução. Quando estudamos a descentralização, sempre estaremos a nos referir apenas ao sistema público da saúde.

As diferenças entre os estados da região referem-se à época em que os mesmos se habilitaram à NOB 96 que define a Gestão Avançada e a Gestão Plena do Sistema Estadual. Mas nem o Rio de Janeiro nem o Espírito Santo se habilitaram a nenhuma das duas até praticamente ser sancionada a NOB 2002. No caso do Espírito Santo, trata-se de um estado pequeno, em termos de população, se comparado com os restantes estados da região Sudeste. Não é o caso do Rio de Janeiro, não somente em termos de população, mas pela importância histórica e a visibilidade que o estado tem no país. O Rio de Janeiro permaneceu até a NOB/Noas 2002, que define a nova modalidade de gestão regionalizada, sem se acolher à forma anterior de gestão sancionada pela NOB 96. Ou seja, passaram seis anos sem se habilitar à Gestão Avançada ou Gestão Plena do Sistema Estadual, sendo que 
ambas as modalidades características da descentralização na esfera estadual já tinham se efetivado praticamente em todos os estados do país.

Algumas considerações complementares merecem ser destacadas a respeito da descentralização da política de saúde no estado:

- As NOBs, instrumentos jurídicos dos quais lançou mão o Ministério da Saúde para a regulamentação da política de saúde, tiveram, desde a CF88, um forte caráter indutor na condução da operacionalização da política e marcada ênfase no nível central;

- O SUS se sustenta num processo gradual para sua efetivação, entendendo-se por descentralização a municipalização como eixo central da política de saúde. Assim, o papel e as atribuições da esfera estadual sancionadas pela NOB 96 ficaram pouco desenhados no processo de municipalização do estado, gerando relações diretas entre municípios e federação;

- A especial configuração e o processo histórico singular na conformação do estado, sob a sua feição atual, acrescentaram à municipalização dificuldades decorrentes da relação entre o estado e o município do Rio de Janeiro. À implementação do SUS se soma a confusão de papéis e atribuições entre ambos e com os municípios do interior do estado. Como resultado de atribuições insuficientemente definidas, os municípios do interior e o próprio município do Rio estabelecem relações diretas com a União, produzindo-se, em alguns casos, avanços significativos no processo de habilitação dos municípios para a gestão local, bem mais acentuados do que os avanços que o próprio estado deveria alcançar em conjunto com os seus municípios.

O Rio de Janeiro pode ser considerado como estado-problema, principalmente pelo incipiente estágio de descentralização do sistema de atenção à saúde, devido, em grande medida, à ausência de políticas mais incisivas e à dependência orçamentária da federação.

Em artigo sobre a CIB - instância de pactuação do estado formulada pela NOB 93, com assento da Secretaria Estadual e do Cosems, composta pelos secretários municipais do Rio de Janeiro -, Dias (2001) procura analisar em que medida a criação desta poderia contribuir para a construção de um pacto federativo. Contrariamente à esperança da autora, não houve o pacto que, em definitivo, é necessário para que o processo de descentralização se realize plenamente.

A autora mostra, ano a ano, desde a implantação da CIB em 1993 até 1998 que houve um funcionamento regular com reuniões periódicas, escolha de representantes, formação da Câmara Técnica, elaborou-se pautas de discussão e até mudou-se o organograma da secretaria estadual, sem que isso significasse que a política saísse efetivamente do papel. Ou seja, não se alcançou uma política comum entre estado e municípios sob a condução da SES e direcionada ao desenvolvimento do SUS.

Não é a ausência de definição de atribuições da esfera estadual que inviabilizou a implementação do SUS no estado. O problema obedece à falta de acordos políticos para 
o andamento de políticas integradas entre instâncias federadas. $O$ estado não assumiu um projeto próprio para a saúde, nem de financiamento, aplicação e fiscalização de recursos capazes de desenvolver o SUS no marco da política nacional de saúde.

As normas operacionais e portarias que regulam e induzem (Gerschman, 2001) a implementação do SUS em estados e municípios configuram uma fina teia sensível e exposta aos dispositivos políticos preexistentes na federação e demais instâncias administrativas de governo. Assim o caráter pactuado do SUS remete à cooperação permanente entre os governos nacional, estaduais e municipais (Viana, Levcovitz \& Dal Poz, 2001). Essa condição, sobre a qual bastante se tem discutido na bibliografia política relativa ao Estado Federativo no Brasil, adquire um valor singular ao considerar a descentralização da política de saúde e seus percalços no estado do Rio de Janeiro.

Como resolver esse dilema? De fato, a política nacional de saúde inicia-se nos gabinetes do governo central. Inclusive, no caso de uma política que, como o SUS, tem decisiva participação de diversas esferas societárias e de governo que se reúnem e deliberam no Conselho Nacional de Saúde (CNS). A deliberação nessa instância significa decidir quais os encaminhamentos para a implementação do SUS nos níveis locais. Ou seja, normas e regulamentações necessariamente levam consigo uma cota alta de centralização política que, junto com seu caráter indutor, incidem sobre o processo decisório local.

No entanto, essa política não se sustenta se a iniciativa estadual e municipal sobre o próprio território e também de aplicação de recursos próprios dos estados e municípios não acontece de forma adequada. Se estados e municípios não gerarem políticas sobre a base de profundos acordos/pactos políticos entre instâncias do sistema de saúde, tornase inviável a sua realização. Até que ponto o papel da federação é de sobredeterminação, se impondo sobre estados e municípios, recriando a centralização da política? Este é um dilema próprio do SUS.

Ao mesmo tempo, não se poderia afirmar que o estado do Rio de Janeiro não desenvolve a descentralização em razão da União retirar as funções que lhe são próprias. No trabalho de Parada, citando entrevistas com duas gestoras, afirma-se que:

O papel indutor para mudança do modelo assistencial vigente (...) tem um viés limitador, quando é adotada uma agenda que não se enquadra nas diretrizes e prioridades federais. Se o estado e/ou município quiser elaborar e implementar suas próprias políticas, tem que investir com recursos próprios. Esse fato só é minimizado com a programação e pactuação integrada se estiver no âmbito da assistência. (Parada, 2002: 59)

A pergunta que cabe é se poderia ser de outra forma, já que não há política de saúde sem iniciativa local e sem investimento próprio. Não cabe esperar que o sistema estadual de saúde se desenvolva no Rio de Janeiro apenas pelas políticas definidas no nível central e pelos recursos que chegam por meio destas, se não ocorrerem políticas específicas para um determinado espaço local e territorial. 
No caso da gestão atual da Secretaria Estadual de Saúde (SES), diferentemente das gestões estaduais no passado, houve visíveis acordos entre o governo estadual e o federal. Nas entrevistas realizadas em 2007, ${ }^{6}$ houve referências às boas relações entre a SES e o governo federal, ao mesmo tempo que certa crítica às atribuições que efetivamente tem a esfera estadual no desenvolvimento do SUS:

Há uma boa relação com o Ministério da Saúde (MS), o estado deve cumprir a política nacional de saúde. O papel do estado é omisso, ficou perdido dentro do sistema de descentralização. Há contradição entre a negociação federal direta com os municípios e a exigência da regionalização. Como obter a regionalização se o MS negocia diretamente com os municípios?

O discurso do gestor denota, de uma parte, a ausência de atribuições delegadas pela federação ao estado no processo de municipalização e, de outra, certa timidez na planificação da política local. Ou seja, paralelamente a uma crítica em nível central da política, parece existir uma diluição das responsabilidades no enfrentamento dos problemas/ desafios locais. A referência ao Plano de Aceleração do Crescimento (PAC) foi bastante frequente e elogiosa, sobretudo por ele constituir uma fonte orçamentária e de emprego para o governo estadual.

O problema da eficácia do SUS no nível estadual e que atravessa e dificulta a gestão estadual da saúde não se explica, sob nosso ponto de vista, no setor da saúde propriamente dito ou no Ministério da Saúde. As dificuldades na implementação do SUS no estado situam-se nas modalidades de exercício político e basicamente eleitorais que os partidos e as lideranças políticas do estado do Rio de Janeiro desenvolveram historicamente na sua atividade governamental e na sua relação com a sociedade.

\section{A Fusão e a Política de Descentralização no Estado DO RIO DE JANEIRO}

Para compreender o escasso desenvolvimento do SUS no estado, especialmente no que se refere à precariedade dos serviços de atenção à saúde, tomamos como chave explicativa a configuração política do estado do Rio de Janeiro, gerada pela fusão entre o estado da Guanabara com o antigo estado.

A transferência da capital para Brasília e a formação do estado da Guanabara no espaço abandonado da sede administrativa da Nação, no início dos anos 60, e a posterior fusão entre o estado da Guanabara e o antigo estado do Rio de Janeiro, operada em 1975 pelo regime autoritário, configuram processos políticos específicos bastante diferenciados dos outros estados da federação.

\footnotetext{
6 Em 2007 foi elaborado, pela autora deste artigo, um projeto preliminar para o desenvolvimento de uma pesquisa sobre a implementação de políticas de saúde no estado do Rio de Janeiro. O desenvolvimento do mesmo incluiu a realização de três entrevistas com assessores do secretário Estadual de Saúde e que são usadas como referência neste capítulo.
} 
O desenho político partidário local/nacional é profundamente marcado pela conjunção de uma vocação/identidade de centro nevrálgico da Nação e pelas mudanças operadas em um período historicamente curto e traumático - pouco mais de dez anos -, sob o qual se forja um sistema partidário local com forte influência no plano nacional, herança de feitos passados, e com forte presença de lideranças locais de inclinações clientelistas, patrimonialistas e cartoriais presentes em ambos os partidos gerados pelo regime militar: Aliança Renovadora Nacional (Arena), partido da situação; e Movimento Democrático Brasileiro (MDB), partido da oposição.

Uma distinção que nos parece extremamente rica para um primeiro mapeamento da política no estado do Rio de Janeiro é estabelecida por Márcio Moreira Alves (2001) - em depoimento publicado em Ferreira, no livro intitulado Crônica Política do Rio de Janeiro ${ }^{7}$ - e se refere à distinção entre a vida política e a vida privada dos políticos.

O que diferencia a vida política da vida dos políticos? A vida política se relaciona à história e trajetória institucional dos partidos políticos; às tradições democráticas ou não destes; às práticas; às plataformas partidárias; às linhas de ação e alianças político-partidárias; ao processo decisório de políticas substantivas e não substantivas. Considere-se que estamos tratando de uma época em que o regime político dominante era o militar, que - por meio de um golpe de Estado, distante dos partidos em exercício de governo, seja no executivo ou no legislativo - fundou um longo interregno autoritário, afastando qualquer tentativa político-partidária de um retorno democrático. A única alternativa possível para os partidos foi aquela aceita e viabilizada pelo próprio regime militar.

Naquela conjuntura, os partidos políticos existentes foram extintos/dissolvidos e parte dos políticos - especialmente aqueles que significavam uma ameaça ao regime militar -, presos e cassados. Após o golpe, são criados, pelo Executivo, dois novos partidos - Arena e $\mathrm{MDB}$-, que permitem que os políticos utilizem essas novas legendas de modo a permanecer agindo, sempre que o façam dentro do permitido, dando origem a uma oposição autorizada no MDB e a uma situação institucional legitimada na Arena.

O estado do Rio de Janeiro, resultado da fusão (1975) entre o estado da Guanabara, antiga Capital Federal (1960) e o antigo estado do Rio de Janeiro, passa a ser um estado único. Nesse, o ex-estado da Guanabara se transforma em município e capital do novo estado resultante da fusão. Naturalmente, esse novo status jurídico e político trouxe mudanças consideráveis que tiveram que ser absorvidas e processadas.

A transformação de dois estados em um propiciou o desaparecimento do estado da Guanabara, que passou a ser município e sede capital do novo estado, enquanto, no antigo estado fluminense, a cidade de Niterói, então capital, é abandonada e substituída pelo novo município do Rio. Cabe mencionar que já havia acontecido, nos anos 70, com a mudança da Capital Federal para Brasília, uma importante alteração da vida política da cidade com significativa perda de espaço e poder político e a consequente transformação da cidade capital em estado da Guanabara.

\footnotetext{
${ }^{7}$ Jornalista político, ex-deputado em 1966, cassado e exilado pelo governo militar em 1968.
} 
Da originária vocação de capital e centro político do país - desde a sua fundação até 1960 quando o presidente Juscelino Kubitschek muda a sede da capital -, o Rio de Janeiro precisa adequar e/ou redimensionar o governo à nova situação. Se pensarmos que a Capital Federal é, em qualquer país, o espelho em que se mira a Nação, não é difícil imaginar o que essa mudança suscitou no governo do Rio de Janeiro e, consequentemente, na sociedade carioca.

A autonomia das cidades capitais é dada por vários motivos interligados. Nelas residem o Executivo, o Legislativo e o Judiciário; as grandes decisões políticas, econômicas e administrativas internas e externas acontecem na capital. Os parâmetros societários e culturais, quando não se trata de uma cidade apenas administrativa, definem não apenas formas do exercício de governo, mas também modalidades comportamentais, culturais e políticas que dizem respeito à tradição local. A cidade do Rio de Janeiro expressava o espírito da Nação: alegre, acolhedora e libertária nos seus costumes e nas suas relações humanas.

Com a fusão, a chaga se reaviva, o Rio de Janeiro deixa de ser estado e se transforma em apenas um município do novo estado do Rio de Janeiro, na época formado por Niterói e pouco mais de quarenta municípios já bastante empobrecidos após a finalização do ciclo econômico do café. Apenas para se ter uma ideia do tamanho do problema, dados relativos ao ano de 1974 mostram que, enquanto o estado da Guanabara arrecadou antes da fusão dois milhões e 249 mil dólares, o estado do Rio alcançou apenas 370 mil dólares.

Sob uma perspectiva sociocultural, uma parte da identidade carioca foi-se com o translado da capital e a outra, com a fusão. A partir desta, a cidade precisou ser novamente redimensionada à nova condição municipal a que se agrega também o fato de se tornar sede do governo estadual em um estado com baixo valor simbólico.

Para tornar ainda mais complexa a fusão, esta foi decidida durante o governo militar pelo então presidente general Geisel através da lei complementar n. 20 de 10 de julho de 1974, sem consulta, inclusive, aos próprios partidos criados pelo regime militar. ${ }^{8}$ Esse processo gerou dificuldades político-administrativas para a efetiva integração do município à política estadual, ainda que no presente prevaleça o esquecimento sobre a origem dessa relação conflituosa, que se atualiza na maneira de lidar com as autonomias entre município e estado e com as relações intergovernamentais dessas instâncias de governo.

Tanto em depoimentos de políticos quanto de jornalistas da época (Motta \& Sarmento, 2001a, 2001b) que tratam da fusão no estado do Rio é bastante controversa a interpretação dos motivos do governo do general Geisel para operar esse processo. O texto de Motta (2001) se refere a um momento do regime em que se propõe um projeto de desenvolvimento econômico, o "Brasil Grande", e uma proposta de distensão. Para a autora, essa proposta exigiria um maior equilíbrio regional, revelado pelo general Geisel e fundado na preocupação do desenvolvimento econômico nacional:

A fusão seria assim a primeira medida da ação governamental no intuito de interferir no equilíbrio federativo. Por um lado, reforçou a proposta das regiões metro-

\footnotetext{
${ }^{8}$ Ver em Motta e Sarmento (2001a, 2001b) depoimentos de políticos do estado do Rio de Janeiro da época.
} 
politanas... como principal elemento dinâmico da federação, na medida em que buscava uma maior integração intermunicipal através da eliminação das barreiras político-institucionais que separavam o núcleo da região - no caso a cidade do Rio de Janeiro - dos 13 municípios... chamados de Grande Rio que se situavam no estado do Rio. Por outro, consolidou um polo de desenvolvimento poderoso no Rio de Janeiro ao criar um estado que poderia vir a dividir com São Paulo a liderança do quadro nacional. (Motta, 2001: 26-27 - grifos meus)

Mas, se a expectativa do regime militar em relação à fusão foi de contribuir para o equilíbrio federativo de modo a contrabalançar a hegemonia econômica paulista e criar um polo de desenvolvimento carioca, não foi isso que efetivamente aconteceu.

O regime militar acreditava que a fusão traria benefícios institucionais ao estado do Rio; equilíbrio entre município, região metropolitana e o restante do estado de modo a gerar um novo arcabouço jurídico político, disseminação do desenvolvimento industrial no interior do estado. Além disso, o regime buscava um novo quadro político fluminense, que diminuísse o peso do MDB - predominante no município - e aumentasse a importância da Arena que tinha maior influência no interior do estado, fundamentalmente nas prefeituras e nas câmaras municipais que, nas eleições de 1972, resultaram majoritariamente da Arena.

As leituras sobre a fusão são bastante controversas e há quem arrisque uma interpretação puramente política sobre a intenção de governo militar. Mais que um novo equilíbrio federativo e a criação de um polo de desenvolvimento que equilibrasse o peso de São Paulo na federação, interessava ao presidente Geisel reforçar a autoridade do poder central e debilitar a oposição e a máquina política no estado: "uma vez que no bojo do projeto estava a nomeação de um interventor federal para o governo do novo estado do Rio de Janeiro. Para isso a medida promoveu a extinção do estado da Guanabara, criada em 1960, como resultado da transferência da capital para Brasília" (Freire, 2001: 58).

Em depoimentos a políticos e jornalistas da época, alguns destes manifestam desconfiança em relação aos motivos da fusão expostos pelo governo Geisel. No depoimento, Mello Franco, político da linha chaguista, manifesta: "acredito que a fusão teve como objetivo esvaziar o conteúdo oposicionista do Rio” (Mello Franco, 2001: 136).

Também em depoimento a lideranças daquele momento, Klabin, prefeito do Rio eleito pela máquina chaguista em 1979 , atribui a fusão a uma decisão essencialmente política, mas a explica diferentemente como lemos a seguir:

A fusão foi consequência de um jogo político malfeito entre Ernani de Amaral Peixoto e o Golberi, porque o Amaral, que se julgava dono do eleitorado do Rio, achava que suplantaria o eleitorado da Guanabara e com isso elegeria quem quisesse. Para surpresa geral, saiu o tiro pela culatra, e o Chagas foi eleito governador do novo estado do Rio de Janeiro... Os mecanismos usados para a implementação da fusão foram todos prejudiciais ao município do Rio de Janeiro. Na divisão de poder entre a Guanabara e o estado do Rio, os princípios utilizados foram os de permuta política, de um lado, a ambição de Tamoio de ser eleito governador, de outro, o Faria Lima que 
estava certo que a fusão seria vitoriosa em termos geopolíticos, o que não aconteceu.

(Klabin, 2001: 194)

A citação explica a fusão sob a perspectiva de um cálculo político equivocado do líder político da Arena, cujas bases de apoio se localizavam no interior fluminense, e do general Golberi Couto e Silva, a quem se atribui a paternidade da ideia da fusão. De fato, Amaral Peixoto era opositor a Chagas Freitas, político originário do estado da Guanabara, (Diniz, 1982), ${ }^{9}$ que montou a sua máquina sobre bases municipais de apoio político. Vários dos depoimentos são bastante esclarecedores a respeito de como os políticos do estado viam o exercício de governo; este se sustentaria na capacidade de influência pessoal que o político era capaz de desenvolver por meio dos seus cabos eleitorais e das benesses que o partido podia distribuir.

A passagem para estado da Guanabara deixou sem resolver o que fazer com os "espólios dos falecidos estado da Guanabara, e do antigo estado do Rio”, e o nascimento de uma nova sede, com status jurídico de município que inclui a região metropolitana, baixada e extensão, trouxe, ainda que com menor força, o espólio da falecida antiga capital do estado: Niterói. Por último, se a integração e o equilíbrio político econômico eram fundamentais para o processo de constituição do Rio de Janeiro, "como tornar complementares, identidades políticas econômicas diferentes e, em alguns casos conflitantes" (Motta, 2001: 31-32).

Estas questões trazem embutidas outras extremamente problemáticas, dentre elas a do esvaziamento do Rio de Janeiro que, ao se transformar em município, sede do novo estado do Rio, esbarrava com a resistência carioca de se integrar ao estado. Além disso, redesenhar o estado do Rio significava enfrentar a divisão de competências e atribuições entre a esfera federal, estadual e municipal, considerando-se que o Rio de Janeiro foi Distrito Federal e muitas das instituições da União permaneceram no estado por bastante tempo, como, por exemplo, o Instituto Nacional Assistência Médica Previdência Social (Inamps), a Fundação Nacional de Saúde (FNS), instituições hospitalares e outras.

O processo de descentralização tal como preconizado pelo SUS constituiu-se numa política extremamente frágil e vulnerável no estado do Rio, na medida em que a sua efetivação depende, como vimos, da cooperação entre os âmbitos administrativos e políticos da União, dos estados e dos municípios. Considerando que esta condição não existe, a sua construção passa a adquirir um valor central.

\section{Máquina Política no Estado do Rio de Janeiro}

No bojo da fusão, constata-se, no plano político, a inviabilidade da integração partidária entre município e estado. A disputa político partidária residia no controle do MDB no estado, entre o ex-governador carioca Chagas Freitas e o senador fluminense Amaral

\footnotetext{
9 A corrente chaguista tem sua origem na política do antigo estado da Guanabara, onde o grupo constituiu-se e consolidou-se a partir de 1964, já na vigência do bipartidarismo. Seu líder começou sua carreira política no Partido Social Progressista de Ademar de Barros (PSP). Ver Diniz (1982).
} 
Peixoto (Motta, 2001). As bases eleitorais eram distribuídas e apropriadas territorialmente pelos políticos dos antigos estados, Chagas Freitas, cuja origem e cujas bases estavam na Guanabara, e o senador Amaral Peixoto, cuja origem e cujas bases eleitorais se localizavam no antigo estado do Rio e, especialmente, da sua capital Niterói. Eram ambos políticos do partido da oposição (Diniz, 1982).

Quanto mais cabos eleitorais distribuídos no território e mais dinheiro de emendas constitucionais ou de outras origens menos virtuosas, melhores condições para o desenvolvimento da máquina e maior poder político para o caudilho do partido.

O governo central se via obrigado a lidar com um estado que tinha se manifestado como oposição, não podendo se desconsiderar o fato de Chagas Freitas - defensor da estadualização da Guanabara - ter sido eleito indiretamente pela Assembleia Legislativa em 1970 para governador da Guanabara.

A propósito da importância do chaguismo, como máquina política no estado, Diniz afirma que: "o salto no movimento ascensional do grupo chaguista situar-se-ia no ano de 1970 quando adquire o controle da Bancada do MDB na Assembleia Estadual conquistando cerca de $85 \%$ das cadeiras e $90 \%$ dos votos dados aos representantes do partido, elegendo ainda mais de 50\%” (Diniz, 1982: 68).

O peso que a máquina política estadual teve nos partidos políticos e nas instituições de governo no estado merece ser tratada, especialmente, considerando que afeta tanto o estado como o município do Rio de Janeiro e para isso vamos nos valer do estudo de Diniz (1982) sobre a máquina política chaguista no estado do Rio de Janeiro.

Começando por algumas considerações sobre o que é, como se constitui uma máquina política e quais as características específicas da máquina chaguista, pareceu-nos interessante reproduzir uma citação, do livro de Diniz, de um autor americano que estudou a máquina política na cidade de Chicago, local onde nasce o conceito político de máquina.

Os políticos dirigentes da máquina são práticos, pragmáticos, paroquialistas e não ideológicos. Sabem que todos os indivíduos e grupos que integram o eleitorado estão preocupados com seus próprios interesses... e jamais esquecem o que foi feito para eles... O suporte enquanto políticos depende do apoio que possam dar a interesses pessoais e privados professando sempre publicamente o bem comum. Deve se tocar o menos possível em questões políticas emocionais porque alguém ganha e alguém perde: aqueles que ganham esquecem mas aqueles que perdem nunca se esquecerão de você. Acima de tudo, não se deve levantar questões de conteúdo ideológico ou filosófico pois este tipo de questões ameaçam os objetivos de permanência no poder. (Rakove, 1975: 8-9)

Aprendida a lição, no Rio de Janeiro, a máquina política chaguista nasce no antigo estado da Guanabara por volta de 1964. Para Diniz (1982), ela se constitui como modalidade de organização complexa que depende do desempenho eleitoral sobre a base de três níveis de organização: um primeiro nível, que se refere ao controle oligárquico do partido que é acionado, manipulando o sistema de filiação e o direito de impugnar afiliações e de controlar os cabos eleitorais, mantendo-se assim o domínio do partido. Um segundo 
nível se refere à capacidade de representação nas bancadas do partido no legislativo estadual, municipal e federal. Um terceiro nível tem a ver com a eficácia da máquina, com o estabelecimento e a consolidação de seus vínculos com o executivo estadual.

A tradição familiar é um traço da máquina chaguista e as vinculações da máquina com grupos religiosos incluem, além da umbanda, alguns ramos do protestantismo como o Batista, a Igreja Universal, a Assembleia de Deus e outros. Mas os vínculos não são apenas religiosos, são também com segmentos das populações urbanas, associações de moradores, escolas de samba e setores profissionais. A articulação entre esfera executiva, parlamentar e partidária constitui aspecto central da máquina. Essas características da máquina chaguista são poderosas e permanecem presentes até hoje, ainda que Chagas Freitas tenha saído da cena política nos finais da década de 1990 (Diniz, 1982).

Os partidos políticos no estado alimentaram uma cultura política e institucional bastante marcada pela fusão e pela vocação de cidade capital do país. A mudança de estado para município não contribuiu para a constituição de uma identidade própria e diferente da que foi no passado. A relação entre a cidade e o estado permaneceu caracterizada por profundas diferenças e vocações, tais como as que referimos quando da discussão sobre o que corresponde ao município do Rio e ao estado em termos de políticas de saúde e responsabilidades. Mais especificamente no que se refere à atenção à saúde e ao funcionamento, investimento, à infraestrura e cobertura dos serviços de saúde.

A modalidade de exercício da política oriunda da máquina chaguista marcou também a futura trajetória do estado e da cidade do Rio de Janeiro. A máquina política dificulta, em grande medida, a incorporação de inovações capazes de definir políticas em outros formatos que não os baseados no clientelismo e no papel das lideranças políticas de cunho tradicional. De fato, a atuação política dos partidos, dos políticos, da própria Assembleia Legislativa e do governo se sustentam sobre a base da troca de favores pessoais e do enriquecimento duvidoso. Esses mecanismos estão profundamente enraizados na política carioca, ao ponto que se tornam naturais os desmandos das autoridades, tais como a formação de 'milícias' que operam de forma paralela ao tráfico de drogas e que são organizadas por políticos socializados na cultura da máquina política criada por Chagas Freitas.

Após a derrota das eleições do seu sucessor, Miro Teixeira, em 1982, Chagas mantém a máquina política até 1999 quando sai do Partido do Movimento Democrático Brasileiro (PMDB) e vai para o Partido Progressita (PP). Mas a máquina criada por ele sobrevive e é alimentada pelos políticos e pela sua dinâmica eleitoral até os dias de hoje.

A modalidade clientelista, personalista e corrupta de se fazer política alimenta a máquina na medida em que se tornou a forma corrente de operar dos partidos políticos cariocas. Poderia se dizer que a máquina partidária se valida e se reproduz no terreno fértil deste novo século, quando a política partidária - programática ou de ideias - ficou perempta e fora de foco. Como colocava Rakove, as máquinas políticas funcionam sobre a base de políticos para os quais nunca deve se falar de ideologia ou se ter motivos ideológicos ou filosóficos para agir na política, "pois tais questões ameaçam os objetivos de permanência no poder" (Rakove, 1975: 9). 
De fato, a política de máquina é um enorme empecilho para o estabelecimento de pactos cooperativos nas esferas estaduais e municipais ao implementar políticas que não servem para sustentar os políticos, mas que são baseadas no exercício da cidadania, na participação societária e na obrigação do estado na atenção pública e universal de saúde. Ou seja, tenha como objetivo diminuir as desigualdades sociais e de saúde numa população tão castigada como a do Rio de Janeiro. Em definitivo, tratar-se-ia de políticas inovadoras para o estabelecimento de uma gestão de governo cooperativo entre estado e municípios tal como definida pelo SUS.

\section{Considerações FinaIs}

A discussão realizada aqui possibilita compreender porque, a partir da fusão, gerou-se uma discussão permanente dos políticos, da imprensa e das instituições políticas do estado e do município na interpretação da origem dos 'problemas' e das atribuições/responsabilidades de governo, tais como: saúde, saneamento e educação. A quem corresponde e o que corresponde a cada uma das esferas administrativas? Quais as responsabilidades do estado e quais as do município? Observa-se um conflito de poderes entre um município que não se integra ao estado, e um estado que oscila no caráter de instância superlativa ao município.

Na nossa compreensão e sob a perspectiva analisada, nasce nos anos 70, com a fusão, um 'conflito federativo' entre município e estado que se alastra até o presente. Conflito mais relacionado à política interna do estado do Rio do que às relações existentes entre federação e estado.

Esse conflito, propriamente estadual, induz a não integração e a disputas entre o estado e o seu município-sede que interferem nas relações federativas e que, dada a não integração, enfraquecem a atuação político-governamental das duas instâncias administrativas. Quando o direcionamento de políticas sociais, como no caso do SUS, prevê como eixo central a descentralização do sistema de saúde nos estados e municípios, a situação se agrava. Nesta condição, se esvai a intervenção e definição do município e do estado na implementação da política de saúde dada a inadequação para a pactuação entre esferas de governo. Abre-se o espaço para o estabelecimento de alianças temporárias e circunstanciais, segundo os interesses políticos em jogo, antes do que à definição das atribuições do município capital e do estado do Rio nas políticas de saúde estaduais.

Em caso de políticas, como o SUS, em que a integração entre esferas de governo é indispensável para o andamento da política, esta tende a se tornar inoperante, não pela ausência do que fazer, mas pela debilidade em pactuar entre instâncias federativas. Esta situação inviabiliza o estabelecimento de uma base consensual/integrada entre papéis e funções a serem desempenhadas pelo governo estadual e as que cabem ao governo municipal.

As trajetórias político-institucionais relacionadas à fusão e às políticas da máquina chaguista alimentaram infindáveis discussões a respeito de atribuições e responsabilidades das políticas públicas e dos serviços de atenção à comunidade correspondentes ao estado 
e ao município do Rio de Janeiro e uma permanente alusão à falta de recursos de ambas as instâncias de governo. Tanto o estado quanto o município se valem desse motivo para justificar as deficiências reiteradas no cumprimento das funções de governo. De fato, a implementação do SUS requer o que não existe até hoje: integração entre município e estado. A autonomia política operacional e financeira do Rio de Janeiro não se põe na berlinda porque município e estado renunciaram a tê-la. Em troca desta, a substituíram pela eterna ladainha da falta de recursos e pela continuidade de instituições estatais que resistem à integração estadual.

Se a questão da saúde e do SUS já é matéria de continuada relevância para a pesquisa científica, o Rio de Janeiro, tanto o estado quanto o município, constituem-se em foco de ainda maior importância, dadas as questões específicas aqui discutidas. De fato, a questão da saúde no Rio é todo um programa de pesquisa apenas iniciado.

\section{REFERÊNCIAS}

ALVES M. M. Depoimento. In: FERREIRA, M. de M. Crônica Política do Rio de Janeiro. Rio de Janeiro: Editora FGV, 2001.

BRASIL. IBGE. Diretoria de Pesquisa, Coordenação de População e Indicadores Sociais. Pesquisa de Assistência Médico Sanitária, 2005.

BRASIL. Ministério da Saúde. Sistema de Informações Hospitalares do SUS (SIH/SUS), 2007.

COMISSÃO DE SECRETÁRIOS MUNICIPAIS (CONASEMS). Boletim do Conselho Nacional de Secretários Municipais de Saúde, jan.-fev. 2007.

DENGUE: descaso com carcaças de carro acaba. O Globo, Rio de Janeiro, 24 nov. 2007.

DENGUE: Niterói investiga duas mortes suspeitas. O Globo, Rio de Janeiro, 20 abr. 2008.

DIAS, L. L. A Comissão Intergestores Bipartite a CIB do Rio de Janeiro. Physis - Revista de Saúde Coletiva, 11(1): 199-252, 2001.

DINIZ, E. Voto e Máquina Política: patronagem e clientelismo no Rio de Janeiro. São Paulo: Paz e Terra, 1982.

FREIRE, A. Evento político e representação parlamentar: a fusão e os senadores da Guanabara e do Rio de Janeiro. In: FREIRE, A.; SARMENTO C. E. \& MOTTA, M. (Orgs.). Um Estado em Questão: os 25 anos do Rio de Janeiro. Rio de Janeiro: Editora FGV, 2001.

GERSCHMAN, S. Municipalização e inovação gerencial: um balanço da década de 1990. Revista Ciência E⿱ Saúde Coletiva, 6(2): 417-434, 2001.

GERSCHMAN, S. Políticas comparadas de saúde suplementar no contexto de sistemas públicos de saúde: União Européia e Brasil. Revista Ciência EZ Saúde Coletiva, 13(5): 1.441-1.452, 2008.

KLABIN, I, Depoimento. In: MOTTA, M. \& SARMENTO, C. E. (Orgs). A Construção de um Estado: a fusão em debate. Rio de Janeiro: FGV, 2001.

MELLO FRANCO, F. Depoimento. In: MOTTA, M. \& SARMENTO, C. E. (Orgs.). A Construção de um Estado: a fusão em debate. Rio de Janeiro: FGV, 2001.

MOTTA, M. A fusão da Guanabara com o estado do Rio: desafios e desencantos. In: FREIRE, A.; SARMENTO, C. E. \& MOTTA, M. (Orgs.). Um Estado em Questão: os 25 anos do Rio de Janeiro. Rio de Janeiro: Editora FGV, 2001.

MOTTA, M. \& SARMENTO, C. E. A Construção de um Estado: a fusão em debate. Rio de Janeiro: FGV, 2001a. 
MOTTA, M., SARMENTO, C. E. A fusão da Guanabara com o estado do Rio: desafios e desencantos. In: FREIRE, A.; SARMENTO C. E. \& MOTTA, M. (Orgs.). Um Estado em Questão: os 25 anos do Rio de Janeiro. Rio de Janeiro: Editora FGV, 2001b.

PARADA, R. Federalismo e o SUS: um estudo sobre as mudanças dos padrões de governabilidade no Rio de Janeiro, 2002. Tese de Doutorado, Rio de Janeiro: Instituto de Medicina Social, Universidade do Estado do Rio de Janeiro.

RAKOVE, M. L. Don't Make no Waves, Don't Back no Losers: an insider's analysis of the daley machine. Bloomington: Indiana University Press, 1975.

SIQUEIRA, A. S. P. Condições Particulares de Transmissão de Dengue na Região Oceânica de Niterói, 2008. Dissertação de Mestrado, Rio de Janeiro: Escola Nacional de Saúde Pública Sergio Arouca, Fundação Oswaldo Cruz.

VIANA, D. A. L.; LEVCOVITZ, E. \& DAL POZ, M. R. O SUS no estado do Rio de Janeiro. Physis - Revista de Saúde Coletiva, 11(1): 11-17, 2001. 